\title{
Impact of Enhanced Input, Pushed Output, and Inner Speech on the Accuracy of EFL Learners under Varying Task Complexities of Content and Language Integrated Learning
}

\author{
Wubalem Abebe Yitbarek
}

Department of English, Faculty of Humanities, Bahir Dar university, P.O. Box: 79, Bahir Dar, Ethiopia

\begin{tabular}{lll}
\hline \multicolumn{1}{c}{ Abstract } & Article Information \\
\hline The integrated teaching of content and language has emerged as one of the recent & Article History: \\
educational practices with promising success in learning outcomes such as critical & Received : 12-05-2015 \\
thinking, lexical gains and genres of academic language. Yet this pedagogical & Revised $: 13-09-2015$ \\
approach faced challenges in drawing the attention of learners to target language & Accepted : 18-09-2015 \\
\cline { 2 - 3 } structures and attaining desired level of target language accuracy. In a move to & Keywords: \\
address this gap, three focus on form pedagogical tools namely, input enhancement, & CLIL \\
pushed output, and inner speech have been experimented in this study. Also, the & Focus on form \\
study examined how degree of task complexity played out with the use of these & Task complexity \\
pedagogical tools. The study employed quasi-experimental design with quantitative & Attention \\
data analysis tools. The results demonstrates that learner inner speech helps to & Accuracy \\
draw the attention of learners to target structures while the remaining two have & *Corresponding Author: \\
limited or no impact. The procedures followed in experimentation of the interventions & Wubalem Abebe Yitbarek \\
lend practical insights on how to fill this gap in CLIL practice. & E-mail: \\
Copyright@2015 STAR Journal, Wollega University. All Rights Reserved. & wubalem1989@gmail.com \\
\hline
\end{tabular}

\section{INTRODUCTION}

The notion of content and language integrated learning (CLIL), also called content-based language instruction (CBI), is one of the significant developments in the world of ESL/ EFL in the past three decades. Emerged as an off shoot of communicative language teaching, this instructional approach seeks to bring the teaching of academic content and target language skills together in a way they reinforce each other.

CLIL derives its theoretical foundation from different theories of language education and sister disciplines in the domains of human learning. The first major theoretical justification for CLIL comes from language teaching theories that come under the umbrella of natural approaches to language instruction (Widowsson,1990; Krashen, 1985; Van Lier, 2000). At the center of these theories is that language is learned most effectively for communication in meaningful and purposeful social and academic contexts. In real life, people use language to talk about what they know and what they want to know more about, not to talk about language itself. What school learners know and need to know more about is the subject matter of school. Therefore, the integration of content and language learning provides real meaning that is an inherent feature of naturalistic language learning. In such contexts, meaning provides cognitive hangers for language functions and structures. Conversely, in the absence of real meaning, language structures and functions are likely to be learned as abstractions devoid of conceptual or communicative value.

The other theoretical basis (still inside Second language acquisition) for this pedagogical approach comes from Krashen's (1982, 1985 and 1994) theory of comprehensible input hypothesis. Krashen in his hypothesis posits that a second language is most successfully acquired when the conditions mirror those present in first language acquisition with the focus more on meaning rather than on form. Learners profit from their learning when the language input is at or just above the competence of the student, and when there is sufficient opportunity for students to engage in meaningful use of that language in a relatively anxiety-free environment. Content \& language integrated instructions are closely linked to these assumptions as the focus of instruction is on the subject matter, and not on the form (Krashen, 1984). Comprehensible input hypothesis provided an early rationale for the development of CLIL and influenced this pedagogical practices leading into the emergence of CLIL programs in many educational settings in the US, Canada and Europe.

Driven by these theoretical justifications, CLIL has become a global pedagogical practice in many educational settings. Also, the CLIL practices across these educational contexts are accompanied with myriads of studies testing the theoretical claims of the approach: experimental studies (Pally,1999; Klahn 1997; Gaffield- 


\section{Wubalem Abebe Yitbarek}

Vile, 1996; Peck 1987; Rodrigo 1997; Stryker 1997), quasi-experimental inquiries (Chadran and Esarey 1997; Dupuy 1996; Hudson 1991; Kasper 1997; Rasper,2000; Sternfeild,1992 and 1993), Case studies (Gee,1997; Benesch, 1988; Bruce, 2002, Song, 2006; James, 2006), Longitudinal Studies (Ruiz de Zarobe, 2008; Baetens Beardsmore, 1993; Coyle,1999), and program evaluation studies (David,2008; Lorenzo et al., 2009; Canado and Luisa, 2010).

These studies address the impact of the pedagogical approach on the development of target language competence across the major modalities of language: academic language skills, oral proficiency, vocabulary learning, reading and listening comprehension, and writing. A closer look into the finding of these studies shows that while CLIL pays off in domains of academic language, critical thinking, oral fluency and listening comprehension, it is still deficient in the area of target language accuracy (Lorenzo, 2000; Harrop, 2008; Dalton-Puffer, 2010). This is largely attributed to two reasons. First, there is an inherent competintion between meaning comprehension and form learning. Also, under normal circumstances human attentional energy is channeled to content learning (comprehension) at the expense of form learning (Van Patten, 1990 and 20004; Skehan,1998). Thus, learners channel their attentional energy to content learning at the expense of language forms. These writers further indicated that in many cases learners do not necessarily utilize syntax in understanding content meanings. They often get the message with a combination of vocabulary, or lexical information plus extra-linguistic information (Harrop, 2008; Lorenzo, 2009).

Other writers (Genesee, 1987; Sternfield, 1989; Lyster, 2004) concur with these writers arguing that prior familiarity with subject matter, coupled with strategies to think about the subject, allows students to rely on concepts familiar in their first language to access those same concepts in the unfamiliar vocabulary and grammar of a second language. Also, as language is adjunct to content emphasis in CLIL syllabus, the focus on content may deny students the opportunity to develop accuracy in the target language.

These challenges facing CLIL practices and the scientific explanations given for these challanges prompted recommendation from CLIL educators for further inquiry. Prticulrly, it is suggested that for CLIL to prove its claims and to secure it place as an educational practice, it needs to come up with pedagogical techniques that take the pedagogical technique beyond these challenges (Lorenzo, 2008; Dalton-puffer, 20007; Swain, 1995). Educators in CLIL need to draw insights from sister disciplines such as cognitive psychology, SLA, and Social learning theories (1), to draw the attention of learners to target language forms and functions while at the same time they are learning academic content, and (2), to employ interventional actions that take learners from meaning negotiation processes to processing of target language functions and structures in oral interactions.

Aligning itself with these recommendations, this study is devoted to exploring the possible pedagogical techniques that can remedy the gap between the CLIL theoretical claims and the unsatisfactory outcomes of the
Sci. Technol. Arts Res. J., July-Sep 2015, 4(3): 230-239

current practice. Thus, while it aims at improving the local CLIL practice, it endeavors to fill the global research gap in this area of pedagogical practice.

To achieve this, it draws insights from cognitive psychology and second language classroom interaction to experiment the role of enhanced input, pushed output, and inner speech for this purpose. The full statement of the problem of the study will be described latter. Now we turn to the theoretical bases and potentialities of these pedagogical techniques.

\section{Theoretical Foundations of Attention Drawing Instructional Techniques}

Taking the central role of attention in language input processing, SLA researchers in the past three decades endeavored into formulating pedagogical techniques that draw the attentional energy of learners to language forms and functions in meaning-driven language learning models. To this end, three pedagogical attention drawing techniques, namely input enhancement, pushed output and the use of leaner inner speech took the center stage in the academic inquiry and the theoretical discourse in this area.

These techniques, while they seek to attain the goal of proportionally channeling of learners' attention to target language forms and meaning, employ distinctive processes to attain this same goal. Also, while each of the techniques fit within the framework of input processing and the integrated learning of content and language, they are premised on competing theoretical foundations.

Input enhancement is one of input modification techniques with the view to raise language intake in the processes of second/foreign language instruction. As such it seeks to draw implicitly and unobtrusively the learners' attention to form contained in a written input (Doughty and Williams,1998). The basic method of the enhancement involves increasing the perceptual salience of the target form via combinations of various formatting techniques (e.g., bolding, capitalizing, or underlining, or colour coding). This may sometimes be accompanied by an explicit mention to the learners to attend to the highlighted language form.

The pedagogical construct of input enhancement was first used by Sharwood (1981) to refer to usage of cues to make learners aware of certain linguistic elements in the input. The idea behind this pedagogical technique is that outside manipulation of input or task materials can create conditions that stimulate internal learning mechanisms so as to advance learners' knowledge of the target language. Thus, The external manipulation of input can affect intake and thus learning. In developing a set of ideas about the possible effects of input on learning, Sharwood $(1993,1991)$ believes that cognitive processes in second language learning are associated with the exposure of the learner to the type of input, which includes the target language system explanations. According to this writer, input enhancement has a decisive role in the input the learners receive and causes L2 proficiency to develop.

Sharwood (2004) elucidate the cognitive processes trigerred by this pedagogical tool based on the tenets of a leaning model called modular growth on-line 


\section{Wubalem Abebe Yitbarek}

growth and language use (MOGUL) model. At the center of this learning model is the claim that language learning input is always composed of language forms (syntax) and semantic stimuli (content meaning). Further, these two components of the learning input are always in competition for accommodation in learners' cognitive systems. As the language input enters into these online processing, it triggers competition among the modules. To this end, the salience of the syntactic elements in the reading input is assumed to serve as an internal priming device to make the syntactic module sufficiently competent with the conceptual module in accommodating the incoming stimuli within it. Particularly, this framework presumes that the saliency of the target features in reading input strike that component of learners working memory (called visiosketpad) responsible for activating visual stimuli. This in turn increases the lilkelyhood for the salient target structures to be integrated into the exiting learner schemata.

A considerable number of studies have been carried out to test the theoretical claims of this pedagogical technique. These studies, which were carried out in nonCLIL settings, operationalized enhanced input in different ways. Some treated it as the main independent variable of interest (Jourdenais, 1998; Leow, 2001) and some have used it as one of several techniques for focus on form instruction (Doughty, 1991; Robinson, 1997).

Looking into the outcomes of the studies vis-a-vis this goal, one could see that many of the studies reported positive outcomes (Alanen, 1995; Lee, 2007; Lee, 2007; Leow, 1997 and 2001; Shook, 1994; Overstreet, 1998; 2002; White, 1998; Wong, 2003), with few (Izumi, 2000; Jourdenais, 1998) reporting non-effect for the use of this pedagogical tool

Apart from input enhancement, two other pedagogical techniques, namely pushed output and inner speech attracted the attention of ESL/EFL writers in terms of their potential to draw the attention of learners to language forms and functions in a meaning driven language learning process.

Pushed output is coined by Swain (1993) to refer to a an interactional process where a more competent interlocutor ( a native speaker a or a teacher) pushes a learner in oral interaction to express his meanings instead of providing him/her immediate explicit feedback. Swain coined this technique as a reaction to some ESL/EFL writers' (Van patten, 1996 and 2004; Sharwood, 1986; Schmidt, 2000) over reliance on input in general and enhanced input in particular to promote learner interlanguage accuracy.

Swain (1993 and 1995) argues that drawing the attention of learners to target language forms is indispensably important to attain learner interlanguage development. Yet this is potentially possible through pushing learners to speak in interactional process involving teacher-learner or learner-learner interactions. This writer further notes that producing the target language through a pushed output may serve as a trigger that forces the learner to pay attention to the means of expression needed in order to successfully convey his or her own intended meaning.
Sci. Technol. Arts Res. J., July-Sep 2015, 4(3): 230-239

This claims attracts support from writers in Psycholinguistics (Levelt, 1989) who argue that pushed output play particularly important roles for learning purposes by functioning as an internal priming device for grammatical consciousness-raising of the language learner. As such the push from the more capable interlocutor (teacher or native speaker) on the learner would heighten the problematicty of expressing meanings on the part of the learner. The heightened sense of problematicity during production may in turn cause the learners to process subsequent input with more focused attention. The learners may try to examine closely how the target language forms express the intention that they just had difficulty in expressing on their own.

These theoretical claims of the pushed output were tested through a number of studies (Izumi and Bigelow, 2000; Izumi, Bigelow, Fujiwara, and Fearnow, 1999). The results from the studies indicated that learners often modify their output in response to the linguistic demands of teacher signals of comprehension difficulty and also suggest that pushing learners to produce more comprehensible output may have a long-term effect Results of the studies focusing on the metalinguistic function of output (Donato, 1994; La Pierre, 1994; Swain, 1995) lend some support to the claim that producing language and reflecting on it in an attempt to create meaning has positive effects on language learning processes.

Despite these promising outcomes, other writers voice their skepticism over the technique. Particularly, they argue that the use of pushed output may make learners anxiety prone in the whole interactional process and this may defeat the entire instructional goals. Also, the use of pushed output is criticized from the point of view of planning time in interactional processes. According to writers such as Morin (1993), Guerero (1994), Tomlinson (2000), Skehan(1998), the technique of pushed output denies learners the resource of planning time in the interactional processes which in turn reduces the language gain in the interactional processes. This down side of the pushed output opens space for the development of pedagogical techniques that cater for more learner autonomy. One such pedagogical technique attracted the attention of language educators is the use of learner inner speech.

The construct of inner speech refers to a self-directed dialogue that an individual makes to herself/herself in silence while processing language input. As such it is a self-regulated learning tool that enable learners (Prior to speaking or writing ) to fix their thoughts in their minds (Guerrero,1994; Tomlinson, 2000). With the aid of inner speech, learners formulate a mental plan or a synopsis of some sort followed by a rehearsal of what they intend to produce. Thus, according to the writers this mental tool allows better space to draw the attention of learners to target language structures and eventually improves target language accuracy .

This argument of Guerrero (1994) and Tomlinson (2000) on inner speech is shared by theoretical support from attention studies (Schimidt,1995). While these writers hold that attention to language forms is indispensably important for language learning, they asserts that what is attended to by the learner in the input becomes intake if the detection of input is followed 


\section{Wubalem Abebe Yitbarek}

by rehearsal and reflections through inner speech. Further, Schmidt (1995) argues that learning situation that allow inner speech help learners to make deeper cognitive processes leading to better comprehension and analysis that one could attain in a dyadic interaction or a mere reading comprehension practice.

Finally, considerable number of language educators provide theoretical and empirical evidences on the role of this learning tool in this respect (Geurrero, 1999; Broner and Tarone, 2001; Tomlinson, 2000; Lantolf , 1997).

\section{The Study}

Aligning itself with the recommendations put forward by researchers in CLIL, this study is devoted to exploring the possible pedagogical techniques that can remedy the gap between the CLIL theoretical claims and the unsatisfactory outcomes of the current practice. Thus, while it aims at improving the local CLIL practice, it endeavors to fill the global research gap in this area of pedagogical practice.

The study has been carried out in Ethiopian CLIL classrooms where the instructional process is handled by content area teachers. In the preliminary assessment of the educational process and the learning outcomes of the local CLIL practice, the researcher found out that (1), learners having passed through the previous CLIL process are deficient in their level of target language accuracy, and (2), the instructional practices of the teachers reduce the teaching of target language structures to a mere incidental level and no instructional technique has been used to draw the attention of learners to target language structures.

Thus, the CLIL practice in Ethiopia share the problems prevalent in other educational settings in the world. Yet no research has been carried out on ways to fill this gap in the instructional practice. The study, therefore, primarily seeks to investigate the role of these pedagogical techniques in drawing the attention of learners to target language forms to the effect of enhancing their accuracy through CLIL tasks.

While this is the primary goal of the study, it addressed the subject of task complexity which is inextricably linked to the variables (attentional energy and target language accuracy) operationalized in the study. Particularly, the degree of task complexity has a role to play in the outcome of attention drawing tools of enhanced input pushed output and inner speech (Krashen, 1985; Robinson, 2001a and 2001b, 2005; Skehan, 1998). A close reading of the arguments show that there are two sets of competing arguments on the relationship between task complexity and the utilization of attentional energy for form learning.

The first argument advanced by Skehan (1998), Van patten (2004) and Foster (2003) holds that cognitively less complex tasks cater for drawing the attention of learner to target language features. This in turn leads to an efficient and balanced utilization of attenntional energy for language learning and content learning. Skehan (1998) in his model, widely known as the tradeoff hypothesis, justified his argument on the ground that attentional resources are limited, and that learners cannot process complex academic concepts and target language feature simultaneously. So, simplified
Sci. Technol. Arts Res. J., July-Sep 2015, 4(3): 230-239

tasks would ease this burden giving room for learners to pay attention to target language features. Skehan and his proponents also make reference to Krashen's comprehensible hypothesis to substantiate their argument. Krashen (1982, 1985, 1994) in his input hypothesis postulates that language learners acquire language when they understand messages or receive comprehensible input. Particularly, when they are provided with comprehensible input, target language structures and functions are automatically available for acquisition.

In contrast to these arguments, others (Robinson, 2001a) and Gilabert (2007) take the view that learners benefit under complex task conditions. Robinson in his learning model, widely known as Cognition hypothesis, claim that as tasks are made more complex, learners stretch their attention, memory, reasoning, and other information processing resources in order to meet the cognitive demands imposed by task design on their processing (Robinson, 2001a, 2001b, 2003, 2005; Wickens, 1992). This, Robinson suggests, has the potential to draw learners' attention to a wider range of vocabulary (lexical complexity), to focus on the way they grammaticize concepts (accuracy) and how they syntaticize them (structural complexity), and to increase interaction.

This controversy is alive in the EFL/ESL literature of input processing and task based learning. Thus this study explores the role of task complexity in the use of such attention drawing tools.

The following research questions have been formulated to guide the investigations of these issues:

- Does the use of enhanced input, pushed output and inner speech across task conditions significantly change learners' target language accuracy ?

- What is the comparative impact of the three pedagogical techniques on learners' target language accuracy across the task conditions?

- Does the degree of task complexity have a differential impact on the accuracy gains of learners?

From these questions, the following two hypotheses were formulated:

$\mathbf{H}_{1}$ : The attention drawing tools will enhance target language accuracy with varying degrees in the following order: Pushed output $>$ enhanced input $>$ inner speech.

$\mathbf{H}_{2}$ : Treatments with simplified task conditions will allow drawing the attention of learners to target language structures more than those of complex task conditions across treatment types.

\section{MATERIALS AND METHODS}

\section{Sampling of Participants}

This study has been carried out in the department of information technology at Bahir Dar poly technique college. This college runs six departments across which the CLIL approach is supposed to be employed. Yet only one department (the department of Information Technology) has sufficient number of students to accommodate the demands of the operationalization of the research. Hence, this department is selected 


\section{Wubalem Abebe Yitbarek}

through convenient sampling technique. All the teachers and students of this department at the college are taken as subjects of the study.

Subject teachers were trained on how to carry out the experimentation on the whole processes of the study. A four weeks of training was delivered to the teachers on how to employ the interventions in the CLIL classes. The teachers use of the interventions has been piloted in the process. The researcher made sure that the teachers could carry out the intervention before intervening in the process.

\section{Research Design}

This study employed a pre-test posttest quasiexperimental design with one control group of students. Operationalized through this design, the study investigated the effect of the three attention drawing tools (enhanced input, pushed output, inner speech) at two levels of task complexity (Simplified and complex task). Through the combination of the two variables, six experimental conditions were established.

Condition 1- Enhanced input + Simplified task

Condition 2- Enhanced input + Complex task

Condition 3- The use of inner speech + complex task

Condition 4- The use of inner speech + simplified task

Condition 5- The use of pushed output + complex task

Condition 6- The use of pushed output + simplified tasks

Control group - Content teaching in English with no use of any pedagogical tool

\section{Task Design and Degree of Task Complexity}

The tasks for each treatment condition derive their input from academic content that students were dealing with at a point where this research was carried out. The student in all of the treatment condition were provided with questions that involve problem solving processes based on their understanding of the concepts in the academic theme presented to them .

The tasks vary in their degree of complexity. These variations were made following the theoretical and empirical parameters set by previous researchers (Foster, 200; Robinson, 2005). As such the simplified tasks differ from the complex tasks in three ways:

(1) the simplified tasks unlike the case in complex tasks, involve provision of meanings of key concept

(2) the learners are made familiarized with the content to be processes by previous reading of the input for two days ( 2 hours each) before carrying out the task.

(3) the input in the simplified tasks, unlike the case in the complex task condition, are supported by visual demonstrations.

Despite these differences, the learners in both task conditions are provided with almost similar questions to answer. The question are set with the intent to invite learners to use the target structures (relative pronouns and simple present tense). These nature of the questions is maintained across treatment types (enhanced input, pushed output and inner speech) with the use of specific question types to fit each treatment process.
Sci. Technol. Arts Res. J., July-Sep 2015, 4(3): 230-239

\section{Treatments Procedures}

The treatment procedures under each treatment condition varies based on the theoretical foundation of the pedagogical intervention employed. To this end, the participants under enhanced input were provided with a reading text in which the target structures were italicized and emboldened. Also, the learners were instructed to pay attention to how the target structures typographically enhanced in the input are used to communicate meaning in the reading text. Finally, they were told that they will be tested on the language forms and the academic content of the text after the treatment.

Turning to the procedures under the pushed output treatment, it involves the following moves of oral interaction.

1) The complex reading text used in the input enhancement condition was taken.

2) From this text, oral interactional tasks were set through the collaboration of the content area teacher and the researcher.

3) Students were prompted to answer these question in a way they use the target structure in their answer. particularly, the question from the teacher is made in a way it draws the attention of the learners to the target form by making it a compulsory element in answering the question orally.

4) The teacher pushes learners to speak by posing clarification requests on the meaning to be conveyed.

5) Up on the learner's failure to express meaning in the target language, the teacher does not provide an immediate feedback. Rather, he/she pushes the learner until he /she runs out of providing a different answer. Finally, the teacher provides the feedback where the learner is unable to produce the correct structure. The teacher makes the push in intervals 5 seconds. The duration for the entire pushing processes can not exceed 15 seconds. This push applies to learners who do not respond to teacher prompts.

Students in the inner speech treatment received a training on how to utilize their inner speech mental processes as a tool to learn language and content simultaneously. Specifically, they were told how inner speech as self-regulated mental process can help them to focus on and discover target language forms while processing meaning. To do this, the following steps were shown for learners which was also followed as treatment procedure.

1) Learnesr were made to read the academic content text used in the earlier two treatments.

2) Then he/she was asked to answer questions drawn from the reading. The questions were framed in a way they compel the learners to use the target structures in their answers.

3) The learner were strictly told that the answers should be correct linguistically as well as in terms of content.

4) The learners were made to answer the question through an inner speech rehearsal in the absence of reading resource. Also, the students were advised to see the gap in their interlanguage through the inner speech rehearsal. 


\section{Wubalem Abebe Yitbarek}

5) Then he/she returned back to the reading to be assisted by the text in terms of language and content feedback. Learners were given a total of ten minutes to do each question.

\section{Post Testing}

To assess the participant's gain of the target structure (the use of relative pronoun), three different written testing measures were used: (1) fill in blank spaces, (2) sentence combination test and (3) a picture-cued sentencecompletion test.

These tests were given in the order shown above. To standardize the testing procedure, the entire test session was directed by a recorded guide. The exact time allocated for the test, including the time interval between test items, was determined on the basis of the re-results and feedback obtained from a series of pilot tests.

These three tests were administered to participants of all treatment conditions with varying level of the task complexity. Also, the control group were tested on these tasks.

\section{Methods of Data Analysis}

The data from the posttest and the pretest were taken and a pretest-posttest mean difference of accuracy scores was computed. Then the effect of each of the attention drawing tools was computed through one
Sci. Technol. Arts Res. J., July-Sep 2015, 4(3): 230-239

sample t-test in which a comparison is made between the accuracy gains of the control group with the pretest- posttest mean difference for each treatment group. Further, a one way ANOVA was run to assess the comparative impact the treatments and the degree of task complexity across the treatment conditions.

\section{RESULTS}

Table 1 show that not all treatment conditions in this study positively impacted the interlanguage accuracy of learners. To this end, treatments under the enhanced input did not affect the accuracy gains of learners both in the simplified $(p, 0.208 ;>0.05) \&$ complex task conditions $(p, 0.368 ;>0.05)$. The pushed output treatment enhance target language accuracy under the simplified task condition $(p, 0.002 ;<0.05)$, but not in the complex task condition $(p, 0.073 ;>0.05)$. Comprehensive positive impact is observed under inner speech treatments. Both the simplified $(p, 0.00 ;<0.05)$ and complex $(p, 0.012 ;<$ 0.05 ) task conditions of the inner speech treatment paid off in target language accuracy gains of the learners. Taken overall, the results in this table supports the relevant hypothesis (hypothesis 1) only partially. Hypothesis one conjuctures that all treatment conditions enhance target language accuracy albeit with some degree of variation. Yet the results show that only three of the treatment conditions showed this result.

Table 1: Target language accuracy gains under each treatment types

\begin{tabular}{|c|c|c|c|c|c|c|}
\hline Treatment type & Groups & $\begin{array}{l}\text { Mean } \\
\text { scores }\end{array}$ & $\mathbf{t}$ & df & $\begin{array}{c}\text { Mean } \\
\text { difference }\end{array}$ & Sign. \\
\hline \multirow{2}{*}{$\begin{array}{l}\text { Enhanced input } \\
\text { with simplified task }\end{array}$} & $\begin{array}{l}\text { Pretest-posttest difference of accuracy scores } \\
\text { under enhanced input with simplified task }\end{array}$ & 0.68 & 1.074 & 30 & \multirow{2}{*}{0.006} & \multirow{2}{*}{0.208} \\
\hline & $\begin{array}{l}\text { Pretest-posttest difference of accuracy scores } \\
\text { under control group }\end{array}$ & 0.62 & 0.494 & 29 & & \\
\hline \multirow{2}{*}{$\begin{array}{l}\text { Enhanced input } \\
\text { with complex task }\end{array}$} & $\begin{array}{l}\text { pretest-posttest difference of accuracy scores } \\
\text { under enhanced input with complex task }\end{array}$ & 0.71 & 0.786 & 30 & \multirow{2}{*}{0.11} & \multirow{2}{*}{0.368} \\
\hline & $\begin{array}{l}\text { Pretest-posttest difference of accuracy scores } \\
\text { under control group }\end{array}$ & 0.62 & 0.494 & 29 & & \\
\hline \multirow{2}{*}{$\begin{array}{l}\text { Pushed output with } \\
\text { simplified task }\end{array}$} & $\begin{array}{l}\text { Pretest-posttest difference of accuracy scores } \\
\text { under control group }\end{array}$ & 0.62 & 0.494 & 29 & \multirow{2}{*}{14.57} & \multirow{2}{*}{0.002} \\
\hline & $\begin{array}{l}\text { Pretest-posttest difference of accuracy scores } \\
\text { under Pushed output with simplified task }\end{array}$ & 15.129 & 20.85 & 33 & & \\
\hline \multirow{2}{*}{$\begin{array}{l}\text { Pushed output with } \\
\text { complex task }\end{array}$} & $\begin{array}{l}\text { Pretest-posttest difference of accuracy scores } \\
\text { under }\end{array}$ & 0.062 & 0.494 & 30 & \multirow{2}{*}{0.390} & \multirow{2}{*}{0.073} \\
\hline & $\begin{array}{l}\text { Pretest-posttest difference of accuracy scores } \\
\text { under control group }\end{array}$ & 0.432 & 1.852 & 33 & & \\
\hline \multirow{2}{*}{$\begin{array}{l}\text { Inner speech with } \\
\text { simplified task }\end{array}$} & $\begin{array}{l}\text { Pretest-posttest difference of accuracy scores } \\
\text { under inner speech with complex task }\end{array}$ & 24.66 & 33.185 & 29 & \multirow{2}{*}{23.13} & \multirow{2}{*}{0.000} \\
\hline & $\begin{array}{l}\text { Pretest-posttest difference of accuracy scores } \\
\text { under control group }\end{array}$ & 0.064 & 0.494 & 30 & & \\
\hline \multirow{2}{*}{$\begin{array}{l}\text { Inner speech with } \\
\text { complex task }\end{array}$} & $\begin{array}{l}\text { Pretest-posttest difference of accuracy scores } \\
\text { under inner speech with simplified task }\end{array}$ & 20.53 & 29 & 43.77 & \multirow{2}{*}{19.043} & \multirow{2}{*}{0.012} \\
\hline & $\begin{array}{l}\text { Pretest-posttest difference of accuracy scores } \\
\text { under control group }\end{array}$ & 0.0645 & 30 & 0.494 & & \\
\hline
\end{tabular}

\section{Comparative Impacts of Treatment Conditions}

Apart from the assessment of the separate effects of each treatment condition, a one-way analysis of variance has been carried to assess the comparative effect of these treatment conditions. The results from this analysis (Table 2) show that there is a significant difference among the impact of the treatment conditions $(F, 643.2$; $p, 0.001)$. Yet it is worth noting that these figures do not clearly show where the specific differences lie. Thus a post Hoc Gabriel test has been computed under Table 3 below to revealed the differences more clearly. 
Table 2: One-way ANOVA results on comparative impacts of treatment conditions across task types

\begin{tabular}{cccccc}
\hline & Sum of Squares & df & Mean Square & F & Sig. \\
\hline Between Groups & 19502.387 & 5 & 3900.477 & & \\
Within Groups & 1091.514 & 180 & 6.064 & & 0.001 \\
\hline Total & 20593.901 & 185 & & &
\end{tabular}

Table 3: Post-Hoc Gabriel test results on the comparative impacts of the attention drawing tools and degree of task complexity

\begin{tabular}{llccc}
\hline \multicolumn{1}{c}{ Grouping treatment (I) } & \multicolumn{1}{c}{ Treatments (J) } & $\begin{array}{c}\text { Mean } \\
\text { difference (I-J) }\end{array}$ & SE & Sig. \\
\hline & Enhanced input with complex task & 0.04274 & 0.63067 & 1.014 \\
& Pushed output with simplified task & $-14.34435^{*}$ & 0.63067 & 0.002 \\
Enhanced input with simplified tasks. & Pushed output with complex task & -0.39559 & 0.61683 & 1.000 \\
& Inner speech with simplified task & $-24.59167^{*}$ & 0.63582 & 0.001 \\
& Inner speech with complex task & $-20.45833^{*}$ & 0.63582 & 0.000 \\
\hline & Pushed output with simplified task & $-14.3871^{*}$ & 0.62548 & 0.012 \\
& Pushed output with complex task & -0.43833 & 0.61153 & 1.000 \\
Enhanced input with complex task & Inner speech with simplified task & $-24.6344^{*}$ & 0.63067 & 0.001 \\
& Inner speech with complex task & $-20.5010^{*}$ & 0.63067 & 0.001 \\
\hline \multirow{3}{*}{ Pushed output with simplified task } & pushed output with complex task & $13.94877^{*}$ & 0.61153 & 0.002 \\
& Inner speech with simplified task & $-10.2473^{*}$ & 0.63067 & 0.045 \\
& Inner speech with complex task & $-6.11398^{*}$ & 0.63067 & 0.001 \\
\hline \multirow{2}{*}{ Pushed output with complex task } & Inner speech with simplified task & -10 & 6.7 & 0.006 \\
& Inner speech with complex task & -9.5 & 7.4 & 0.000 \\
\hline Inner speech with simplified task & inner speech with complex task & 4.13333 & 0.63582 & 0.0045 \\
\hline
\end{tabular}

Looking into the results in Table 3, we see that the inner speech with simplified tasks yielded the highest impact on the accuracy gain of learners. This is evident in the mean differences and level of significance between the scores of this treatment condition. The scores are significantly better than the rest of the treatment conditions $(p<0.05)$. This is followed by inner speech with complex task treatments. The later is better than the rest of the treatment conditions except the complex task condition of the inner speech treatment category. The simplified task condition of pushed output takes the third place in its impact on target language accuracy. The complex task condition of pushed output is only better than the enhanced input treatments which demonstrate no impact of the desired learning outcome.

Thus, these results lend no support to relevant hypothesis in the study. This hypothesis conjunctures that while all the treatment condition could have an impact on target language accuracy, those under the pushed output category would better pay off. Yet looking into the results, the pushed output treatments in general are less productive (MD, -10.2473, -6.11398 and $-10 ; p<0.05$ ) than the inner speech treatments $(10.2473,6.11398$, and $10 ; p<0.05)$

Now we turn to the role of degree of task complexity in determining the learning gains of target language accuracy. The figures in this same table above show that gains in target language accuracy vary with variations in task complexity. Yet the variations are not largely consistent with the hypothesis set out on this subject earlier in the study. The hypothesis on the role of task complexity predicts that degree of task complexity has a role to play in drawing the attention of learners to target language forms and in allowing them to make changes in their target language accuracy. To this effect, it has been hypothesized that simplified tasks would cater for better accuracy gains across the three attention drawing pedagogical tools (enhanced input, pushed output, and inner speech).

Yet the results in indicate that not all simple task conditions are superior to complex task conditions in yielding the desired learning outcome. Looking into each of the treatment conditions, we see that complex task conditions under inner speech treatment had slightly better impact $(p, 0.045)$ than that under the simple task condition of the same category $(p, 0.22)$. The situation under enhanced input condition also shows that the two task conditions had an insignificant difference. In both task conditions of enhanced input treatments the learners demonstrated very little or no change in their target language accuracy ( $p, 0.95$ and 0.97$)$.

Evidences in support of the hypothesis is observed only under the pushed output treatment. Under this treatment condition, learners under simplified task condition gained significantly more accuracy scores $(p$, $0.036)$ than those under the complex task condition $(p$, 0.77 ). In sum, the results on the role of the attention drawing tools and degree of task complexity did not fully support the hypotheses formulated in the study.

\section{DISCUSSION}

The results in this study by and large show only a partial success story in remedying the deficiency of CLIL instructional processes with respect to gains in target language accuracy. In this section the results will be discussed in light of the theoretical bases on which the interventions were operationalized. To this end, the 


\section{Wubalem Abebe Yitbarek}

outcomes for each treatment condition will be taken in turn for discussion beginning with those found out under the pushed output treatment.

We recall that learners under the pushed output treatments attained varying degree of target language accuracy based on the degree of task complexity involved in the intervention. While learners who were pushed to speak in simple task conditions were drawn to target language structures to the effect of attaining accuracy, those under complex task conditions were not significantly able to restructure their intrlanguage systems. From the these results, two set of explanation can be inferred. First, the claims of Swain's (1995) output hypothesis over the role of pushed output proved positive impact better than visual enhanced input does under the simplified task condition. Particularly, learners' engagement in pushed output promotes deeper, more syntactic processing of the target forms by the learners, as opposed to more semantic processing of input.

To the confirmation of the claims of Swain's (1995) output hypothesis, the evidences suggest that the prompt (Push) brought the participants to their attention something they need to discover about their use of the target language structure (Swain, 1995). Apart from its effect on noticing, the pedagogical actions under this treatment condition serves as a metalinguistic and hypothesis testing functions. As learners notice the gap in their interlanguage they reflect upon their own target language use enabling them to control and internalize linguistic knowledge (Swain, 1995). At this point it is worth noting that learners under the simple pushed output treatment condition, like those under simple enhanced input conditions, manipulate a simplified task with a comprehensible content.

Yet, this role of the pushed output is at least constrained by task complexity in this study in that learners could make this change under the simple task condition of the pushed output treatment. Thus, the results lend partial support to Swain's (1995) output hypothesis, bringing positive impact only under simplified task conditions. The results are also in conflict with the claims of Robinson's (2005) cognition hypothesis and in agreement with Skehan's (1998) tradeoff hypothesis.

Turning to the results under inner speech treatments, we see that participants under this treatment category attain marked accuracy gains far significantly better than the other treatment types. These results suggest that the mental tool of inner speech as a self-directed language practice draws the attention of learners to target structures and it triggers them into further input processing resulting in interlanguagechanges.

These sets of data lend strong support to the theoretical claims of the inner speech learning model. Writers (Tomlinson, 2000; Guerrero, 1999) claim that inner speech is the bases for social speech. Prior to speaking or writing to others, learners, in one way or the other, fix their thoughts in their minds and channel their attentional energy to a desired end through what Geurrero (2000) calls a voluntary attention allocations system. Further, where there is a deliberate pedagogical action in the learning process allowing the utilizationof inner speech, learners benefit much from the use of this mental tool.
Sci. Technol. Arts Res. J., July-Sep 2015, 4(3): 230-239

In the treatment condition under this category, learners were engaged in four-stage input processing allowing the use of inner speech as a principal learning tool. The series of steps involved in the treatment processes of this study allow sufficient space for optimal accomplishment of content comprehension and syntactic interlanguage restructuring. This is evident in the learners' success (unlike their counterparts under pushed output treatment) in accomplishing both the macro level and micro level input processing. Particularly, learners under the complex task condition of the inner speech treatment manage to conceptualize the content meanings, map the meanings into verbal representations, notice the gap in target language grammatical through the monitoring component of the input processing. We recall that learners under the complex task condition of the pushed output treatment could only carry out the macro level processing (comprehension and noticing of syntactic gaps).

This differences of accuracy gains under complex task conditions of the pushed output and inner speech treatments can be attributed to the difference in the input processing time resource available for the two group of learners. Particularly, while participants under the inner speech treatment have sufficient space for strategic planning and rehearsal of their output, those under the pushed output treatment could not afford to do this. This is because the pushed output treatment learners were under pressured condition where they had to respond to the questions or clarifications of meanings with instantaneous prompts. Thus, they have less room to plan and rehearse their output specially under these task conditions that involve the manipulation of complex meanings. Therefore, the learning outcomes at least in the immediate situations is limited to noticing their gaps in their use of the target structures.

Finally, it is worth considering the explanation behind the relative inefficiency of enhanced input in attaining the desired goal of accuracy. We recall that results under enhanced input treatments yielded relatively the least amount of accuracy gains compared to the remaining two category of treatment condition (pushed output and inner speech).

This differential effect of the pedagogical tools lends support to the theoretical underpinnings that justify the superior potentialities of production-based practices in learner interlanguage accuracy. Those models accounting for the role of pushed output and inner speech is premised on the hypothesis that change in learner target language syntax is not driven by interaction between the reading input stimuli and mental modules outlined in the MOGUL framework. Rather, this change in learner interlanguage syntax results from cognitive process in which the learner struggle to parse content meaning into target language syntax through production practices. Learners in the pushed output and the inner speech groups, unlike those in enhanced input, are put in cognitive processing situations where they pass through the stages of conceptualizing content ideas, formulation of ideas into syntactic patterns and articulation of an output. Apart from this, learners in both groups are prompted into producing correct language output. In the case of pushed output the learners are pushed by their teachers to reformulate their utterances until a point they fail to produce anything different. In cases where inner speech is used, learners are made to use their inner 


\section{Wubalem Abebe Yitbarek}

speech as a tool to produce target structures and to self-monitor their output in terms of the gap in it and how to fill this gap. Thus, these features of the outputbased pedagogical actions give learners the chance to access syntactic knowledge of target language better than what comprehension based practices do.

\section{CONCLUSIONS}

This study is primarily motivated by the challenges facing the integrated teaching of content and language at a local and global leve. This pedagogical approach, while it demonstrated promising impacts in other areas of language skills, is found to be deficient in equipping learners with the required level of target language accuracy. In a move to explore pedagogical tools addressing this gap, an input based (enhanced input) and output driven (pushed output and inner speech) pedagogical interventions have been employed. Also, the study explored how these interventional actions play out with degree of task complexity within this instructional processes. Looking into the outcomes, the input based interventional actions failed to remedy the deficiency of the CLIL instructional processes. The pushed output intervention has also limited impact. Only the inner speech treatment demonstrated significant remedy for the deficiencies of this instructional approach.

Degree of task complexity is found to have influenced the impact of the interventional actions only under the oral pushed output practice. In the remaining two interventional treatments the influence is not visible. Taken over all, the result of the study show that drawing the attention of learners to target language forms and attaining accuracy in CLIL instructional processes remains a challenge. Accordingly, more studies are needed to explore the role of the two pedagogical tools (enhanced input and the complex task conditions of pushed output). Particularly, the role of enhanced input need to be explored in combination with brief explicit teaching on the form and function of target structures. This brief explicit teaching can be made prior to exposing the learners to the typographically enhanced reading input.

Also, the complex task condition of the pushed out treatment need to be explored further by incorporating the variable of planning time in the production and processing of the output. That is, whether provision of more planning time during oral production rather than a simple push to speak would help for improvement in target accuracy. Finally, more inquiry is needed in learner related factors such as motivation and working memory capacity of learners at different levels. This is because the motivation of learners and their level of working memory capacity may be the reason for the failure of some of the interventions in this study rather than the pedagogical tools themselves.

\section{Conflict of Interest}

Conflict of interest none declared.

\section{REFERENCES}

Dalton-Puffer, C. (2007a). Academic language functions in a CLIL environment. In: D. Marsh and D. Wolff (Eds.) Diverse contexts-converging goals (pp. 201-210). rankfurt, Germany: Peter Lang.
Sci. Technol. Arts Res. J., July-Sep 2015, 4(3): 230-239

Dalton-Puffer, C. (2007b). Discourse in content and language integrated learning (CLIL) classrooms. Amsterdam, the Netherlands: John Benjamins.

Dalton-Puffer, C. and Nikula, T. (2006). Pragmatics of content-based instruction:teacher and student directives in Finnish and Austrian classrooms. Applied Linguistics 27(2): 241-267.

Doughty, C. (1991). Second language instruction does make a difference: Evidence from and empirical study of relativization. Studies in Second Language Acquisition 13: 431-469.

Doughty, C., and Williams, J. (1998). Focus on form in classroom. Second language acquisition. New York: Cambridge University Press.

Ellis, R. (2003). Task-based language learning and teaching Oxford: Oxford University

Foster, P., and Skehan, P. (1996). The influence of planning time on performance in task-based learning. Studies in Second Language Acquisition 18: 299-234.

Gilabert, P. (2007). The simultaneous manipulation of task complexity along planning time and [+/- Here-and-Now]: Effects on L2 oral production. In: M.P. Garcia Mayo (Ed.), Investigating tasks in formal language learning (pp. 4468). Clevedon:Multilingual Matters.

Guerrero, M.C.M. de. (1994). Form and functions of inner speech in adult second Language learning. In: J.P. Lantolf and G. Appel (Eds.),Vygotskian approaches to second language research (pp.83-115). Norwood, NJ: Ablex.

Guerrero, M.C.M.de. (1999). Inner speech as mental rehea rsal: The case of Advanced L2 learners. Issues in Applied Linguistics 10: 27-55.

Guerrero, M.C.M.de. (2000). Activating the ZPD: Mutual scaffolding in L2 peer revision. The Modern Language Journal 84: 51-68.

Harrop, E. (2012). Content and Language Integrated Learning (CLIL): Limitations and Possibilities. Encuentro 21: $57-70$.

Izumi, S, (2000). Promoting noticing and SLA: An empirical study of the effects of output and input enhancement on ESL relativization. Unpublished doctoral dissertation, Georgetown University, Washington, DC.

Izumi, S. (2002). Output, input enhancement, and the noticing hypothesis: An experimental study of ESL relativization. Studies in Second Language Acquisition, 24, 541-577.

James, M.A. (2006). Transfer of learning from a university content-based EAP course. TESOL Quarterly 40(4): 783805.

Jourdenais, R. (1998). The effects of textual enhancement on the acquisition of the Spanish preterit and imperfect. Unpublished doctoral dissertation, georgetown University, Washington, DC.

Jourdenais, R., Ota, M., Stauffer, S., Boyson, B., andDupuy, Beatrice. (1996) Promoting Language and Literacy in the Intermediate French Classroom: The Effects of an Extensive Reading Program. Paper presented at the 1996 MLA Convention, Washington DC. (December).

Kasper, L. (1997). The Impact of Content-Based Instructional Programs on the Academic Progress of ESL Students. English for Specific Purposes 16: 309-320.

Krashen, S. D. (1982). Principles and practice in second language acquisition. Oxford: Pergamon. 


\section{Wubalem Abebe Yitbarek}

Krashen, S.D. (1985). The input hypothesis. London: Longman.

Krashen, S.D. and Terrell, S. (1983). The natural approach: Language acquisition in the classroom. Hayward CA: Alemany Press.

Lantolf, J.P. (2002). Sociocultural theory and second language acquisition. In: R.B. Kaplan (Ed.), Oxford handbook of applied linguistics (pp. 104-114). Oxford, UK: Oxford University Press.

Lantolf, J.P. and Yanez, M.C. (2003). Talking your self in Spanish: Private speech and second language learning. Hispania 86: 97-109.

Leow, R.P. (1997). Attention, awareness, and foreign language behavior. Language Learning 47: 467-505.

Lorenzo, F. (2007). An Analytical Framework of Language Integration in L2 Content-Based Courses: The European Dimension. Language and Education 21: 502-514.

Overstreet, M. (2002). The effects of textual enhancement on second language learner reading comprehension and form recognition. Unpublished doctoral dissertation, University of Illinois, Urbana-Champaign.

Robinson, P. (1995). Attention, memory and the 'noticing' hypothesis. Language Learning 45: 283-331.

Robinson, P. (2001a). Task complexity, cognitive resources, and syllabus design: A triadic framework for examining task influences on SLA. In: P. Robinson (Ed.), Cognition and second language instruction (pp. 287-318). Cambridge, UK: Cambridge University.

Robinson, P. (2001b). Task complexity, task difficulty, and task production: Exploring interactions in a componential framework. Applied Linguistics 22: 27-57.

Schmidt, R.W. (1994a). Deconstructing consciousness in search of useful definitions for applied Linguistics. AILA Review 11: 11-26.

Schmidt, R.W. (1994b). Implicit learning and the cognitive unconscious: of artificial grammars and SLA. In N. C. Ellis (Ed.), Implicit and Explicit Learning of Languages (pp. 165-209). San Diego, CA: Academic Press.

Schmidt, R.W. (1995). Consciousness and Foreign Language learning: A tutorial on the role of attention and awareness in learning. In: R. Schmidt (Ed), Attention and Awareness in Foreign Language Learning (pp. 1-65). Honolulu: University of Hawaii Press.

Sharwood, S.M. (1993). Input enhancement in instructed SLA: Theoretical bases. Studies in Second Language Acquisition 15: 165-179.
Sci. Technol. Arts Res. J., July-Sep 2015, 4(3): 230-239

Sharwood, S.M. (2004). In two minds about grammar: On the interaction of linguistic and metalinguistic knowledge in performance. Transactions of the Philological Society 102: $255-280$.

Sharwood, S.M. (2008). Revisiting the role of consciousness with MOGUL. In: Z. Han (Ed). Understanding second language processes (pp. 1-15). Clevedon: Multilingual Matters.

Skehan, P. (1996). A framework for the implementation of task-based instruction. Applied Linguistics 17(1): 38-62.

Skehan, P. (1998). A cognitive approach to language learning. Oxford, UK: Oxford University.

Skehan, P., and Foster, P. (2001). Cognition and tasks. In: P. Robinson (Ed.), Cognition and second language instruction (pp. 183-205). Cambridge, UK: Cambridge University.

Swain, M. and Sharon Lapkin. (1989). Canadian Immersion and Adult Second Language Teaching: What's the Connection?" The Modern Language Journal 73: 150-59.

Swain, M. (1985). Communicative competence: Some roles of comprehensible input and comprehensible output in its development. In: S. Gass, and C. Madden (Eds.), Input in Second language acquisition (pp. 235-253). Rowley, MA: Newbury House.

Swain, M. (1995). Three functions of output in second language learning. In G. Cook, and B. Seidlhofer (Eds.), Principles and practice in applied linguistics: Studies in honour of H.G. Widdowson (pp. 125-144).New York: Oxford University Press.

Tomlinson, B. (2000). Talking toy ourself. The role of the inner voice in language learning. Applied Language Learning 11: 123-154.

Tomlinson,B. (2001). The inner voice: A critical factor inL2 learning. Journal of the Imagination in Language Learning and Teaching 6: 78-93.

VanPatten, B. (1990). Attending to form and content in the input: An experiment in Consciousness. Studies in Second Language Acquisition 12: 287-301.

VanPatten, B. (1996). Input processing and grammar instruction: Theory and research.Norwood, NJ: Ablex.

VanPatten, B. (2004). Input processing in SLA. Lawrence Erlbaum Associates. 